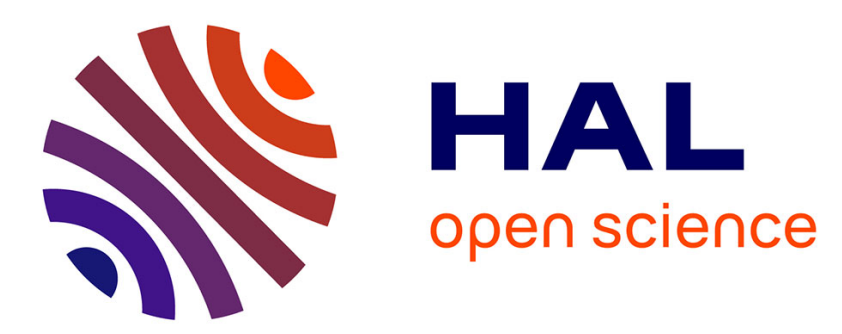

\title{
The Effect of Temperature and Specimen Geometry on the Parameters of the "Local Approach" to Cleavage Fracture
}

\author{
C. Wiesner, M. Goldthorpe
}

\section{- To cite this version:}

C. Wiesner, M. Goldthorpe. The Effect of Temperature and Specimen Geometry on the Parameters of the "Local Approach" to Cleavage Fracture. Journal de Physique IV Proceedings, 1996, 06 (C6), pp.C6-295-C6-304. 10.1051/jp4:1996629 . jpa-00254457

\section{HAL Id: jpa-00254457 https://hal.science/jpa-00254457}

Submitted on 1 Jan 1996

HAL is a multi-disciplinary open access archive for the deposit and dissemination of scientific research documents, whether they are published or not. The documents may come from teaching and research institutions in France or abroad, or from public or private research centers.
L'archive ouverte pluridisciplinaire HAL, est destinée au dépôt et à la diffusion de documents scientifiques de niveau recherche, publiés ou non, émanant des établissements d'enseignement et de recherche français ou étrangers, des laboratoires publics ou privés. 


\title{
The Effect of Temperature and Specimen Geometry on the Parameters of the "Local Approach" to Cleavage Fracture
}

\author{
C.S. Wiesner and M.R. Goldthorpe \\ TWI, Abington Hall, Abington, Cambridge CB1 6AL, U.K.
}

\begin{abstract}
The present work investigates the temperature and specimen geometry dependence of the Weibull parameters of a structural steel (BS 4360 Grade 50D). Notched tensile, notched (Charpy-type) four point bend and fracture mechanics specimens have been used to study the effect of specimen geometry. Axisymmetric and two and three-dimensional finite element analyses have been carried out to determine Weibull parameters for the three specimen types at various temperatures. The results have shown that the parameters determined using notched tensile specimens can be regarded as temperature independent. However, the parameters determined using notched bend and fracture mechanics specimens exhibited some dependence on temperature. There were also differences between the Weibull parameters determined from the different specimen geometries. The results show that there is a need to further develop the 'Local Approach' to cleavage fracture to incorporate effects of temperature and plastic constraint. At present, it is recommended that fracture mechanics specimens be used for the determination of Weibull parameters if the results are to be applied to cracked structures.
\end{abstract}

\section{INTRODUCTION}

The 'Local Approach' to cleavage fracture is a micromechanical failure model to predict the fracture behaviour of specimens and structures first proposed by Beremin [1]. Fracture is assumed to take place in a flawed region of material when a critical stress state is reached. Since the fracture event is described locally, it is possible to deal with non-symmetrical and non-isothermal loading conditions, and the effect of temperature, strain rate and constraint can be readily accommodated. The method and applications of the 'Local Approach' to cleavage fracture has been reviewed by one of the authors [2].

The 'Local Approach' for cleavage fracture is based on the weakest link concept which postulates that failure of a body of material containing a large number of statistically independent elements is triggered by the failure of one of the elements. The cumulative survival probability of the body under consideration is then given by (see Ref.2 for details):

$$
1-P_{f}=\exp \left[-\left(\sigma_{w} / \sigma_{u}\right)^{n}\right]
$$

where $1-P_{\mathrm{f}}$ is the survival probability, $\sigma_{\mathrm{w}}$ is the so-called Weibull stress given by:

$$
\sigma_{w}^{m}=1 / V_{o} \int_{V_{p}} \sigma_{1, i}^{m} d V_{p}
$$

$\sigma_{u}$, the Weibull distribution scale parameter, is a particular value of the cleavage fracture stress, $m$ is the Weibull distribution shape parameter, $V_{o}$ is an arbitrarily chosen volume element, typically $10^{-3} \mathrm{~mm}^{3}, V_{p}$ is the plastic zone volume and $\sigma_{1, \mathrm{i}}$ is the maximum principal tensile stress acting in the volume element $d V_{p}$. In this work, $\sigma_{u}$ and $m$ will be referred to as the Weibull parameters. Two of the areas which were identified in Ref. 2 as needing further attention, are whether or not the Weibull parameters are dependent on specimen geometry and temperature. 
The theory predicts that the statistical distribution of the Weibull stress at cleavage failure (and so the Weibull parameters) is unique for a material and thus independent of specimen geometry and dimension, crack size and shape, and loading mode as long as these parameters are correctly implemented in the finite element analysis (FEA). For notched tensile specimens containing different root radii, the lack of effect of triaxiality on the 'Local Approach' material parameters, $m$ and $\sigma_{u}$, has been demonstrated $[1,3]$. Nevertheless, further work is needed to demonstrate clearly whether the parameters are identical when measured on different types of specimens. Whereas Qu et al [4] and Hou et al [5] found identical values for different specimen types (albeit using semi-analytical methods), Brückner-Foit [6] and Bernauer [7] found different Weibull parameters, when using different specimens geometries. Further, it has been widely assumed that the 'Local Approach' material parameters are independent of temperature, and DiFant et al. [8] have demonstrated temperature independence of $\sigma_{u}$ for the notched tensile specimen configuration. Nevertheless, this assumption has been shown to be somewhat disputed $[7,9]$.

This work contributes to this issue by investigating the dependence of the Weibull parameters on specimen geometry and temperature. A large number of experiments and analyses were carried out on notched tensile, notched bend and fracture mechanics specimens at different lower shelf temperatures of a ferritic structural C-Mn steel to BS 4360:1979 Grade 50D. The results were analysed using the 'Local Approach' to cleavage fracture in its present state of development without attempting to modify its basic definitions.

\section{EXPERIMENTAL METHODS AND RESULTS}

The chemical composition of the material is shown in Table 1 . The microstructure of the parent steel at approximately mid-thickness position is shown in Fig.1.

Table 1 Chemical analysis of steel investigated (plate Section 2A51/7, from Ref.10), in wt\%

\begin{tabular}{||l|l|l|l|l|l|l|l|l||}
\hline $\mathrm{C}$ & $\mathrm{S}$ & $\mathrm{P}$ & $\mathrm{Si}$ & $\mathrm{Mn}$ & $\mathrm{Ni}$ & $\mathrm{Cr}$ & $\mathrm{Mo}$ & $\mathrm{V}$ \\
\hline 0.17 & $<0.005$ & 0.008 & 0.30 & 1.44 & 0.24 & 0.21 & 0.04 & $<0.01$ \\
\hline
\end{tabular}

\begin{tabular}{|l|l|l|l|l|l|l|l|l||}
\hline $\mathrm{Cu}$ & $\mathrm{Nb}$ & $\mathrm{Ti}$ & $\mathrm{Al}$ & $\mathrm{B}$ & $\mathrm{Sn}$ & $\mathrm{Co}$ & $\mathrm{O}$ & $\mathrm{N}$ \\
\hline 0.11 & $<0.005$ & 0.006 & 0.027 & $<0.005$ & 0.01 & $<0.01$ & 0.004 & 0.009 \\
\hline
\end{tabular}

Special efforts were made to obtain accurate stress/strain data for the investigated material as input for FEA. In addition, it is known that local true strains in the notch tip region of bend specimens can exceed $100 \%$; therefore, it was necessary to record stress/strain data at such strain levels. A special waisted specimen geometry was therefore chosen together with diametral contraction measurements. The specimen configuration is shown in Fig.2.

The most widely used geometry for the determination of the Weibull parameter employed is the notched tensile specimen configuration, mainly because this geometry can be analysed by axisymmetric FEA. The notched tensile specimen geometry employed in the present study is shown in Fig.2.

The tensile specimens were tested in a horizontal servohydraulic testing rig, with temperature control by liquid nitrogen vapour. A diametral clip determined the actual diameter of the waisted and necked region throughout the test. Following necking, the true stresses in the necked region of the waisted tensile specimens were corrected for the triaxial stress state using the Bridgman relation. Three tensile tests each were carried out at $-196^{\circ} \mathrm{C},-165^{\circ} \mathrm{C}$ and $-130^{\circ} \mathrm{C}$. True stress/true plastic strain curves were calculated and are shown in Fig.3, the range of results is also indicated by error bars. 
Twenty notched tensile tests each were carried out at $-196,-165$ and $-130^{\circ} \mathrm{C}$. The average failure stress is plotted versus the average failure, $\varepsilon_{i}$, strain in Fig.4 (determined from clip gauge measurements using $\varepsilon_{\mathrm{f}}=2 \ln \left(D_{o} / D\right)$, where $D_{o}$ and $D$ are initial and final notch region diameter).

Four-point notched bend specimens were also tested. The specimen geometry is shown in Fig.2. The geometry is identical to a Charpy specimen configuration with the exception of the notch angle, which was $52^{\circ}$ rather than $45^{\circ}$. Special attention was given to the surface finish in the notched and waisted area of all tensile and bend specimens.

The Charpy-type four-point bend specimens were tested at a ram rate of $0.5 \mathrm{~mm} / \mathrm{min}$ using a double clip testing arrangement. Sixty tests were carried out at the above temperatures. The measured lower clip gauge displacement values at failure are plotted versus the test temperature in Fig.5.

Finally, a total of twenty-seven $12.5 \mathrm{~mm}, 25 \mathrm{~mm}$ B x $2 \mathrm{~B}$ and $50 \mathrm{~mm}$ thick B x B 3-point bend SENB fracture mechanics specimens conforming to BS7448:1991 were tested at the above three temperatures. Additional $J$-results at -120 and $-65^{\circ} \mathrm{C}$ were available from a previous project [10]. The results are summarised in the fracture toughness transition curve shown in Fig.6.

The applied displacement rate in all tests was chosen such that the elastic strain rate in the notch of all specimens was similar.

The failure probability of all tests was calculated [11] using:

$P_{f}=(i-0.5) / N$

Where $i$ is the rank of the experiment (i.e, $i=1$ for lowest and $i=N$ for highest value) and $N$ is the total number of tests.

\section{FINITE ELEMENT ANALYSES}

Axisymmetric and 2D and 3D elastic-plastic finite element stress analyses were carried out on the specimen geometries employed in the present study. The commercial general purpose finite element package ABAQUS version 5.5 [12] was used for all calculations.

The analyses were carried out employing the properties determined at the three test temperatures. For the notched tensile specimens at -165 and $-196^{\circ} \mathrm{C}$, the measured stress-strain curves were modified to obtain good comparison between experimental and numerical load-displacement curves.

The calculated principal stress distribution in the notched tensile specimens exhibited its maximum value well away from the root of the notch at strains below $1 \%$. Thus, it is considered unlikely that any surface effects could have influenced tests which failed at strains exceeding 1\% (compare Ref.13).

The four-point bend Charpy-type specimen was modelled using plane strain two-dimensional and threedimensional models. A minimum mesh size of $250 \mu \mathrm{m}$ was used. The fracture mechanics specimens were modelled with a minimum mesh size of $50 \mu \mathrm{m}$ using both $2 \mathrm{D}$ plane strain and $3 \mathrm{D}$ analyses. 


\section{DETERMINATION OF 'LOCAL APPROACH' PARAMETERS}

\subsection{Determination Procedure}

Specimens are tested in the cleavage fracture regime and suitable mechanical parameters are recorded. Finite element analyses of the different specimen geometries, are carried out to calculate the Weibull stress (Eq.(3)) as a function of the appropriate mechanical parameter. The Weibull stress is calculated from finite element analysis results in a post processor program. In essence, it calculates the Weibull stress, $\sigma_{\mathrm{w}}$, from the finite element analysis output using the following relation:

$$
\sigma_{W}^{m}=1 / V_{o} \sum_{j=1}^{n} \sigma_{1, j}^{m} V_{j}
$$

where the summation is carried out over the $n$ finite element integration stations within the instantaneous plastic zone of the finite element mesh, $V_{j}$ is the volume and $\sigma_{1, j}$ the maximum principal stress associated with integration station $j$, and $m$ and $V_{o}$ are the assumed Weibull shape parameter and a characteristic volume, typically taken as $10^{-3} \mathrm{~mm}^{3} . \sigma_{1, j}$ is averaged over each element. Equation (4) is the discontinuous form of Eq.(2).

Together with the Weibull stress, the post processor lists a suitable mechanical parameter of the finite element model which can be used to link the point of failure of a specimen with the numerically predicted Weibull stress at that point. For notch tensile specimen, the diametral contraction, $\Delta \mathrm{D}$, and the average stress, $\sigma_{\mathrm{av}}$ in the notch plane has been used, for the Charpy-type specimens the lower clip gauge displacement, the load line displacement (LLD) and the notch mouth opening displacement (NMOD). For the fracture mechanics specimens, the $J$-integral value determined according to BS7448:Part 1:1991 was employed.

The Weibull stress distribution, Eq.(1), contains three parameters, namely $V_{o}, m$ and $\sigma_{u} . V_{o}$ was chosen as $10^{-3} \mathrm{~mm}^{3}$. The procedure for the determination of the Weibull parameters, $m$ and $\sigma_{u}$, is summarised in Fig.7. For this initial calculation, an estimate of $m$, designated $\hat{m}$, is used. Using the calculated relation between the Weibull stress and the appropriate mechanical parameter, the Weibull stress at rupture, $\sigma_{w, j}$, is determined from the measured failure points for each test. The statistical sample of $\sigma_{w, i}$ at rupture can then be used to calculate the Weibull parameters, $m$ and $\sigma_{u}$, using the maximum likelihood method [e.g. $14,15]$ to assess whether the assumed value of $\hat{m}$ describes the experimental sample of Weibull stress, $\sigma_{w, i}$, at failure. The iterative process is stopped when the assumed $\hat{m}$ corresponds (within \pm 0.1 for the present work) to the $m$-value obtained from the analysis of the sample $\sigma_{w, i}$.

\subsection{Results}

\subsubsection{Notched Tensile Specimens}

The Weibull stress distributions of the notched tensile specimens calculated for the three test temperatures are plotted in Fig.8. The resulting Weibull parameters are shown in Table 2.

Table 2 shows that similar values were obtained for $m$ and $\sigma_{u}$ at different test temperatures, $\sigma_{\mathfrak{u}}$ but the values depend on the mechanical linking parameter used: lower values for $m$ and higher values for $\sigma_{u}$ are obtained when using the average stress in the notch region as compared to the diametral contraction. 
Table 2 Weibull parameters determined in present study $\left(V_{0}=10^{-3} \mathrm{~mm}^{3}\right)$

\begin{tabular}{|c|c|c|c|c|c|c|c|}
\hline $\begin{array}{l}\text { Specimen } \\
\text { type }\end{array}$ & $\begin{array}{l}\text { Linking } \\
\text { parameter }\end{array}$ & Correction & $\begin{array}{l}\text { No. of } \\
\text { data }\end{array}$ & $\begin{array}{l}\text { Temp, } \\
{ }^{\circ} \mathrm{C}\end{array}$ & $m$ & $\begin{array}{l}\sigma_{\mathrm{n}} \\
\mathrm{MPa}\end{array}$ & Remarks \\
\hline NT & $\begin{array}{l}\Delta D(1) \\
\sigma_{\mathrm{av}}(3) \\
\Delta D\end{array}$ & $\begin{array}{l}\text { None } \\
\text { None } \\
2.5 \%<\varepsilon_{\mathrm{f}}<38 \%(2) \\
\text { None } \\
\text { None } \\
\varepsilon_{\mathrm{f}}<38 \% \\
2.5 \%<\varepsilon_{\mathrm{f}}<38 \%\end{array}$ & $\begin{array}{l}20 \\
20 \\
14 \\
17 \\
20 \\
13 \\
49\end{array}$ & $\begin{array}{l}-196 \\
-165 \\
-130 \\
-196 \\
-165 \\
-130 \\
\text { All }\end{array}$ & $\begin{array}{l}19.8 \\
22.8 \\
20.1 \\
14.7 \\
19.0 \\
17.3 \\
13.2\end{array}$ & $\begin{array}{l}2671 \\
2369 \\
2562 \\
3355 \\
2722 \\
2829 \\
2760 \\
\end{array}$ & \\
\hline Charpy & $\begin{array}{l}\text { Clip displ. } \\
\text { NMOD } \\
\text { LLD }\end{array}$ & $\begin{array}{l}\text { None } \\
\text { None } \\
\text { Clip }<1.8 \mathrm{~mm} \\
\text { None } \\
\text { None } \\
\text { None } \\
\text { NMOD }<1.4 \mathrm{~mm} \\
\text { None }\end{array}$ & $\begin{array}{l}20 \\
21 \\
16 \\
20 \\
21 \\
21 \\
16 \\
21\end{array}$ & $\begin{array}{l}-196 \\
-165 \\
-130 \\
-196 \\
-165 \\
-165 \\
-130 \\
-165\end{array}$ & $\begin{array}{l}36.9 \\
38.8 \\
57.6 \\
39.8 \\
38.7 \\
37.0 \\
59.5 \\
39.4\end{array}$ & $\begin{array}{l}2173 \\
1905 \\
1640 \\
2120 \\
1917 \\
1901 \\
1609 \\
1825\end{array}$ & $\begin{array}{l}\text { 3D } \\
\text { 3D } \\
\text { 3D(4) } \\
\text { 3D } \\
\text { 2D plane strain } \\
\text { 3D } \\
\text { 3D(4) } \\
\text { 3D }\end{array}$ \\
\hline SENB & $J(5)$ & $\begin{array}{l}\text { None } \\
\text { None } \\
\text { None } \\
\text { None } \\
\text { None } \\
\text { Only cleavage } \\
\text { results }\end{array}$ & $\begin{array}{c}9 \\
8 \\
10 \\
10 \\
41 \\
38\end{array}$ & $\begin{array}{r}-196 \\
-165 \\
-130 \\
-130 \\
-120 \\
-65\end{array}$ & $\begin{array}{l}11.0 \\
(6) \\
16.6 \\
13.8 \\
15.6 \\
48.9\end{array}$ & $\begin{array}{l}3471 \\
(6) \\
2607 \\
2787 \\
2470 \\
1669\end{array}$ & $\begin{array}{l}\text { 2D plane strain } \\
\text { 2D plane strain } \\
\text { 2D plane strain } \\
\text { 3D } \\
\text { 2D plane strain } \\
\text { 3D }\end{array}$ \\
\hline
\end{tabular}

Notes: (1) Diametral contraction, (2) Average failure strain, (3) Average failure stress, (4) Preliminary result, experimental and FEA load-clip curves differ, (5) $J$ as per BS7448:1991, (6) No convergence

\subsubsection{Charpy-Type Specimens}

Figure 9 shows the Weibull stress distribution of the Charpy-type specimen. The resulting Weibull parameters are included in Table 2. Whilst the parameters are more or less consistent at -196 and $-165^{\circ} \mathrm{C}$, the -130 data indicated a marked increase for the value of $m$ and a decrease of the value of $\sigma_{u}$. However, the results obtained from different linking parameters and from $2 \mathrm{D}$ analysis are very similar. Table 2 also shows that the absolute values of the Weibull parameters are different to the results from the notched tensile specimens.

\subsubsection{SENB Fracture Mechanics Specimens}

The Weibull stress distributions of the SENB tests are shown in Fig.10, the resulting Weibull parameters are included in Table 2 . For the tests at $-165^{\circ}$, convergence in the iteration procedure to determine the Weibull parameters could not be achieved. However, the data indicate a clear trend of increasing $m$ and decreasing $\sigma_{u}$ values with increasing temperature; there is also a difference in the absolute values of the parameters between SENB and Charpy-type and notched tensile specimens.

In addition, values for $m$ were also determined using the following analytical expression relating to the predicted toughness, $K_{\text {Ic }}$, with the yield strength, $\sigma_{\mathrm{y}}$ :

$$
1-P_{f}=\exp -\left(K_{I c}^{4} B \sigma_{y}^{m-4} C_{m} /\left(V_{o} \sigma_{u}^{m}\right)\right)
$$


and

$\ln \left(K_{I c}\right)=(4-m) / 4 \ln \left(\sigma_{y}\right)+\ln \left(V \sigma_{u}^{m} \ln \left(1 /\left(1-P_{f}\right) /\left(B C_{m}\right)\right)\right.$

Thus, $m$ These can be obtained from a plot of $\ln \left(\mathrm{K}_{\mathrm{Ic}}\right)$ versus $\ln \left(\sigma_{\mathrm{y}}\right)$. Using the data shown in Fig.3 and 6 (up to $-120^{\circ} \mathrm{C}$ only), the above analyses gave values $m=$ of $11.2,11.5$ and 10.4 for thicknesses of $12.5 \mathrm{~mm}, 25 \mathrm{~mm}$ and $50 \mathrm{~mm}$, respectively. These values are in good agreement with the values in Table 2 from SENB specimens at temperatures between $-96^{\circ} \mathrm{C}$ and $-120^{\circ} \mathrm{C}$

\section{DISCUSSION}

In principle, the experimental methods employed for the determination of 'Local Approach' parameters to cleavage fracture are straightforward. Relatively simple notched tensile or notch bend specimens are prepared and tested at lower shelf temperatures. However, care has to be taken when preparing the notched regions of the specimens to ensure that the surface layers beneath the notch root is not affected by the machining operation.

The determination of accurate tensile properties is of utmost importance for the successful application of the 'Local Approach' methodology. Despite taking great care in the design and execution of the tensile tests, some questions still remain as to the accuracy of the tensile properties determined because the FEA of the notched specimens did not result in a perfect match to the experimental data at some temperatures. There is thus still the need for further development for the measurement of tensile properties, especially following the onset of necking.

Two points are of interest regarding the procedure to determine the 'Local Approach' parameters. The first is the equation to calculate the cumulative failure probability of the ranked Weibull stress sample, see Eq.(3). Other equations have been proposed and have been compared [11] as to their descriptive capability, but it was concluded that Eq.(3) is most appropriate for the description of data with a Weibull distribution. The second issue is the choice of the statistical method used to determine the $m$ value from the statistical sample of Weibull stress values at failure. It is now generally accepted that a linear regression analysis of a linearised Weibull plot is biased towards the data at lower failure probabilities $[15,16]$. The maximum likelihood has been suggested to overcome these problems $[6,16]$ and has been used successfully in [17] to determine Weibull parameters. The maximum likelihood method is most affected by the data in the $30 \%$ to $90 \%$ failure probability range. In the present work, a simplified maximum likelihood method was employed, as presented in Ref.14.

Table 2 shows that the Weibull parameters vary considerably depending on test temperature and specimen geometry. (Note that not all tests have been included in the statistical sample for the determination of Weibull parameters. The present work is concerned with the cleavage fracture model, and specimens which may have been, or were affected by ductile failure mechanisms prior to cleavage, were omitted from the sample. Furthermore, for Charpy specimens failing at very low clip openings, for which the maximum of the stress distribution is located at the specimen surface, the possibility cannot be excluded that the failure event may have been affected by surface irregularities or flaws. Based on the FEA stress distribution, the lowest result at $-196^{\circ} \mathrm{C}$ was excluded from the analyses). 
From Table 2 it can be seen that the results for the notched tensile specimens are roughly independent of temperature. Theoretically, the Weibull stresses determined at different temperatures (see Eq.(2)) are affected by both the decrease of the maximum principal stress, $\sigma_{1}$, and the increase of the process zone volume, $V_{p}$. The net effect of these opposite trends has been stated to be negligible [18], thus leading to independent Weibull parameters. There is, however, a marked difference between the parameters determined from the diametral clip readings and the average failure stress values. In this context, it is interesting to refer to some results of a European Structural Integrity Society (ESIS) Technical Committee 8 (TC8) round-robin on numerical aspects of micromechanical methods [19], where Weibull parameters from notched tensile tests using both the diametral contraction and the applied force at failure gave also markedly different results.

In contrast to the notched tensile specimens, the 'Local Approach' parameters determined from the Charpy-type four point bend and the fracture mechanics specimens were considerably more varied, see Table 2 and Fig.11. There was a trend of increasing value of $m$ and decreasing value of $\sigma_{u}$ with increasing temperature.

With respect to the comparison of the different specimen geometries, $m$ is greater and $\sigma_{u}$ smaller for Charpy-type specimens than for notched tensile specimens. However, the Weibull parameters from fracture mechanics SENB specimens are roughly comparable to those determined from notched tensile specimens at the same temperatures, although the SENB results at $-65^{\circ} \mathrm{C}$ indicate a more marked temperature dependence of $\sigma_{u}$ compared to notched tensile specimens (see Fig.11). The trends obtained confirm results by other workers [6,7] who determined differing Weibull parameters from different specimen configurations. Bernauer [7] tested the effect of ductile damage preceding cleavage fracture and principal and equivalent strain corrections without succeeding in unifying the resulting Weibull stress distribution. Whilst the effect of such strain correction was not investigated in the present study, the results nevertheless indicate the need to further develop the Weibull stress definition to include effects due to temperature, plastic strain and/or stress gradients.

\section{SUMMARY, CONCLUSIONS AND RECOMMENDATIONS}

An experimental and analytical programme was carried out to study the effect of temperature and specimen geometry on the Weibull parameters of 'Local Approach' to cleavage fracture. From the results and their discussion, the following conclusions and recommendations are made:

1. The accurate determination of the tensile properties at the temperature of interest is of utmost importance for the application of the 'Local Approach' to cleavage fracture.

2. For the notched tensile specimen geometry, there was no significant effect of temperature on the value of the Weibull parameters.

3. The data sets of the Charpy-type notched bend and the SENB specimens for which convergence was achieved indicated that $m$ increased and $\sigma_{u}$ decreased with increasing temperature.

4. The values of $m$ and $\sigma_{u}$ from notched tensile specimens differed from those determined from Charpytype and SENB specimens.

5. Further work is required to incorporate suitable plastic constraint and/or temperature dependent parameter(s) into the equation for the calculation of the Weibull stress to make it truly transferable between different specimen geometries. 
6. At the present state of development of the model, it is recommended to use a cracked configuration for the determination of Weibull parameters if the results are to be applied to cracked structures.

\section{Acknowledgements}

Useful discussions with Dr A Brückner-Foit (Kemforschungszentrum Karlsruhe), Dr F Minami (University of Osaka), Dr M DiFant (IRSID), G Bernauer (IWM) and N Cardinal (British Steel) are acknowledged gratefully. The work was funded by the Industrial Members of TWI within the framework of TWI's Core Research Programme (CRP).

\section{References}

[1] Beremin F M., Met Trans, Vol.14A (1983), pp.2277-2287.

[2] Wiesner C S., "The 'Local Approach' to cleavage fracture - Concepts and Applications", Abington Publishing, Abington, Cambridge, UK.

[3] Al Mundheri M., Soulat P., Pineau A., "Rupture fragile et ductile de l'acier 16 MN D5: effect de l'iradiation", Proc. 'Int Seminar on 'Local Approach' of Fracture', pp.243-256, Electricité de France, 1986.

[4] Qu D., Wang X W., Tsai C K., "On the Weibull model of cleavage fracture", Proc. Int. Conf. on Mech. Behaviour of Material (Carlsson and Oulson, Eds), pp.779-785, Pergamon, 1983.

[5] Hou C., Cai Q., Su Y., Zheng X., "Volume effect on cleavage strength microstructure and fracture micromechanisms of welded 15 Mn V N steel", Proc. Conf. ICF6, pp.1415-1422, Pergamon, 1984.

[6] Brückner-Foit A, Private communication, November 1992, December 1994

[7] Bernauer G., "Weibull-Analysen des Spaltbruchverhaltens im Übergangsbereich", IWM-Bericht $T$ 2/95, Fraunhofer IWM, Freiburg, January 1995.

[8] DiFant M., Carius H., Carollo G., Cleizergues O., Le Coq V., Mudry F., "Local approach to brittle fracture: discussion of the effect of temperature and strain on the critical cleavage stress", Proc. The IOM 2nd Griffith Conference, Sheffield, UK, The Institute of Materials, 1995.

[9] Bakker A., Koers R W J., "Prediction of cleavage fracture events in the brittle-ductile transition region of a ferritic steel", ESIS/EGF 9, pp 613-632, MEP, London, pp 192-210.

[10] Towers O L., Williams S., Harrison J D., "ECSC collaborative elastic-plastic fracture toughness testing and assessment methods", ECSC Report Eur 9552 EN 1985.

[11] Bergman B., Journal of Materials Science Letters, Vol.3, (1984), pp.689-692.

[12] ABAQUS User's Manuals, Version 5.5, Hibbitt, Karlsson and Sorenson Inc., 1080 Main Street, Pawtucket, Rhode Island, USA, 1995.

[13] Mudry F., DiFant M., "A round-robin on the measurement of local criteria", BCR Report EUR15352 EN, 1994.

[14] Metals Handbook, 9th Edition, Vol.8: "Mechanical testing", Chapter 'Statistics and data analysis', American Society for Metals, Metals Park, OH, 1989.

[15] Masson J J., Bourgain E., Int. J. Fract., Vol.55 (1992), pp.303-319.

[16] Minami F, Private communication, December 1994.

[17] Minami F, Brückner-Foit A, Munz D, Trolldenier B: Int. Journ. Fract. Vol 54 (1992), pp.197-210.

[18] Pineau A, Discussion at ECF10, Berlin, September 1994.

[19] Anon., "Preliminary results of the ESIS TC8 numerical round-robin on micromechanical models", Presented at ECF10, Berlin, Germany, 1994. 

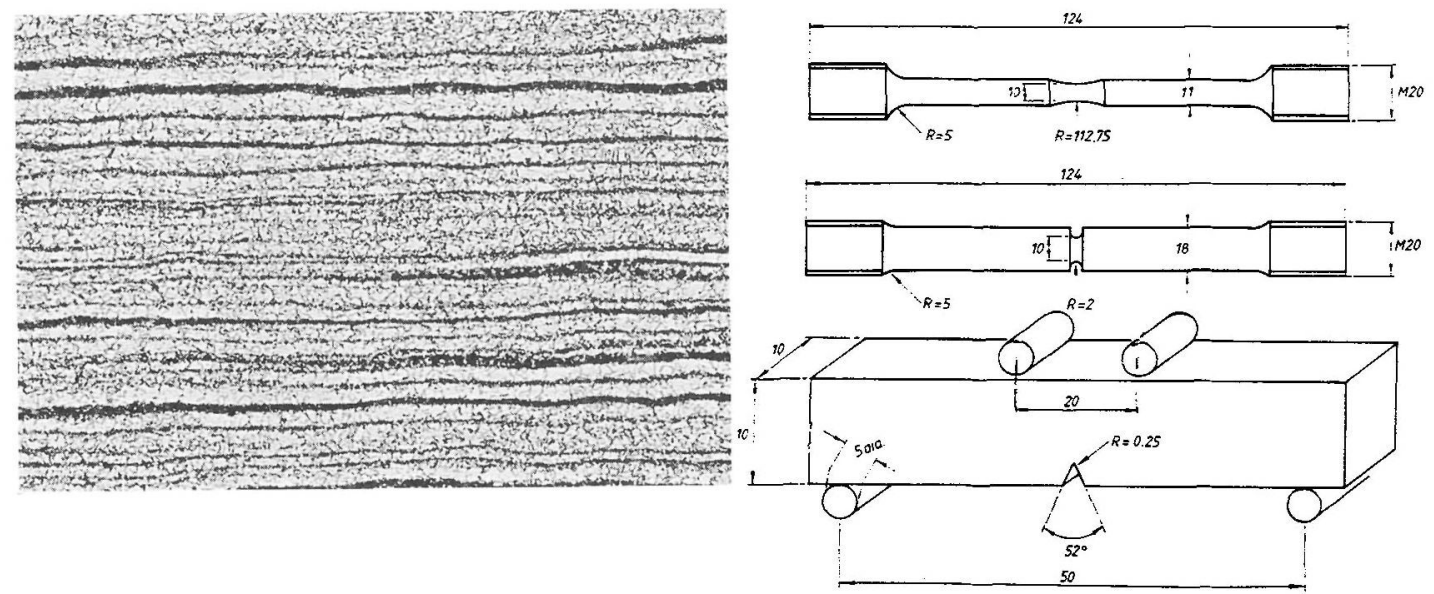

Fig.1 Plate microstructure at mid-thickness position $\mathrm{x} 50$.

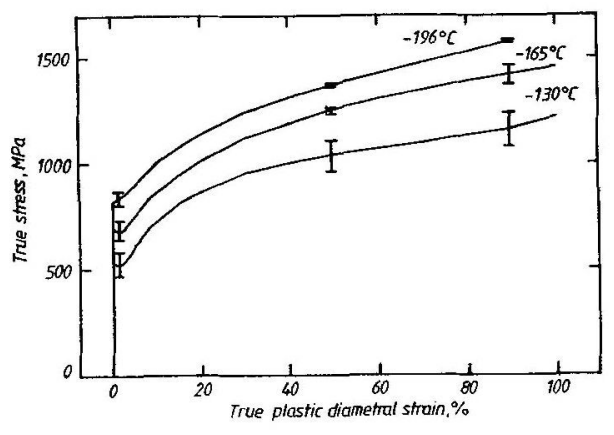

Fig.3 True stress/plastic strain curves for steel studied.

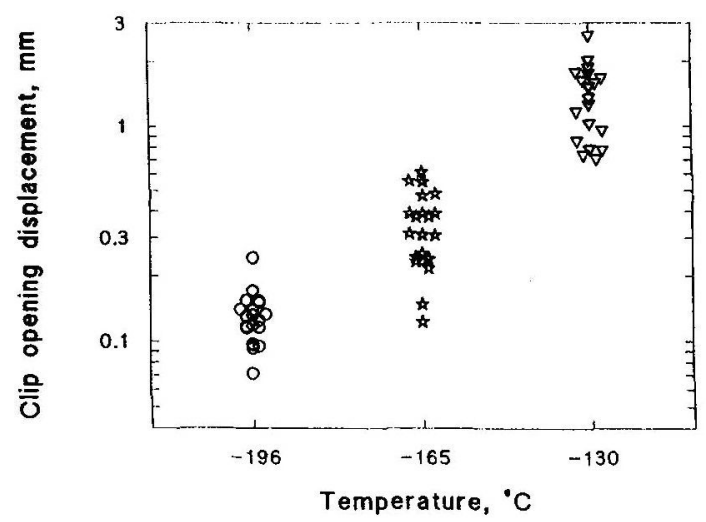

Fig. 2 Geometry of waisted and notched tensile specimens, and Charpy-type notched bend specimens.

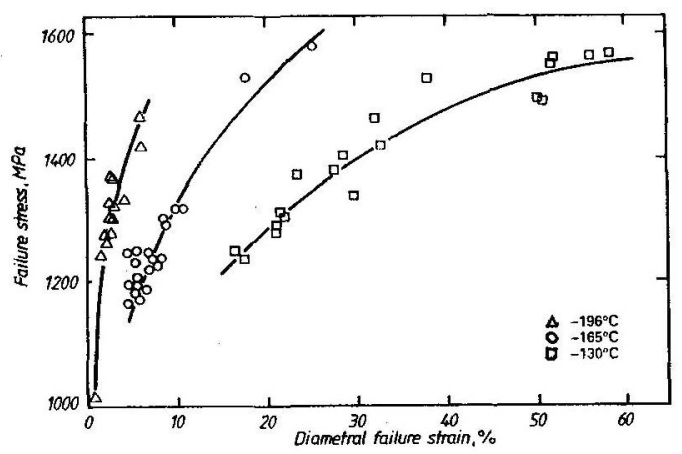

Fig.4 The (average) failure stress of notched tensile specimens versus (average) diametral failure strain.

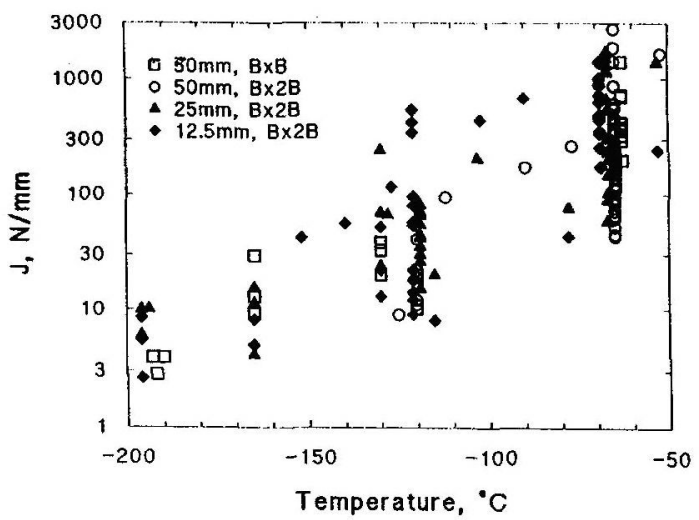

Fig.6 Fracture toughness (in terms of J) transition curves.
Fig.5 Clip gauge opening displacement values at failure of Charpy-type specimens versus temperature. 


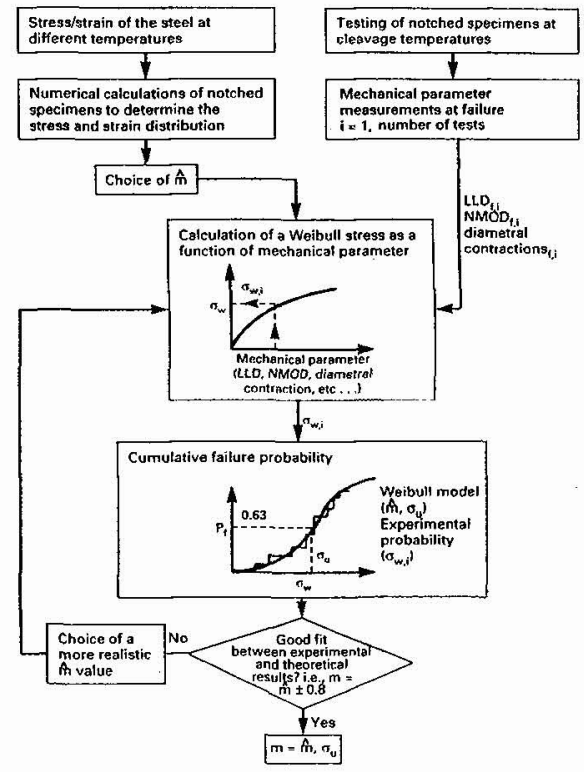

Fig.7 Procedure to determine Weibull parameters from experimental and FEA results.

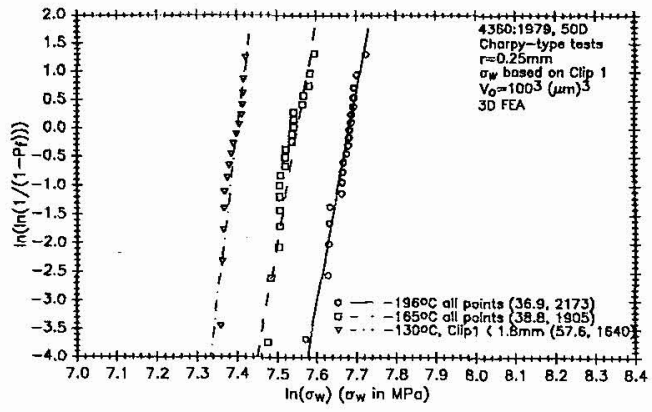

Fig.9 Weibull stress distribution of Charpy-type notched bend specimens at three temperatures.

$(\stackrel{*}{)}$

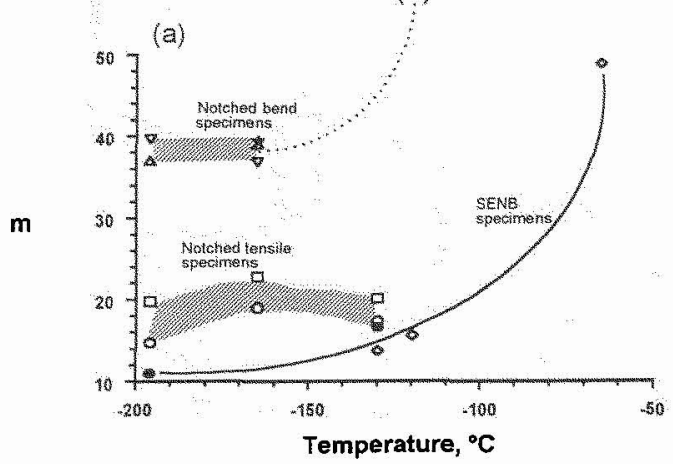

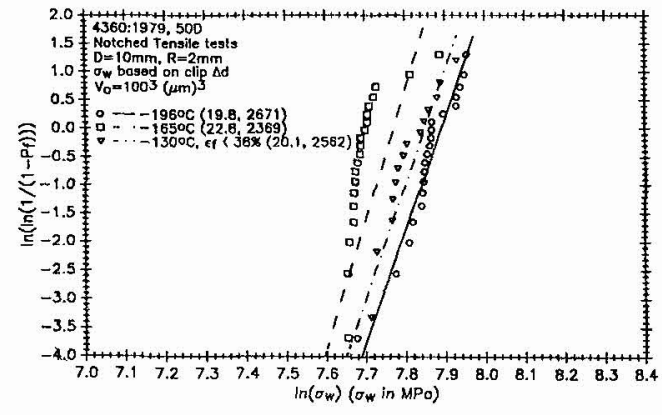

Fig.8 Weibull stress distribution of notched tensile specimens at three temperatures.

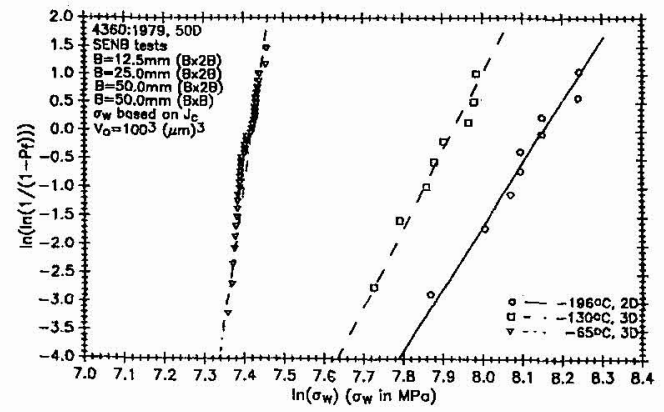

Fig.10 Weibull stress distribution of SENB specimens at three temperatures.

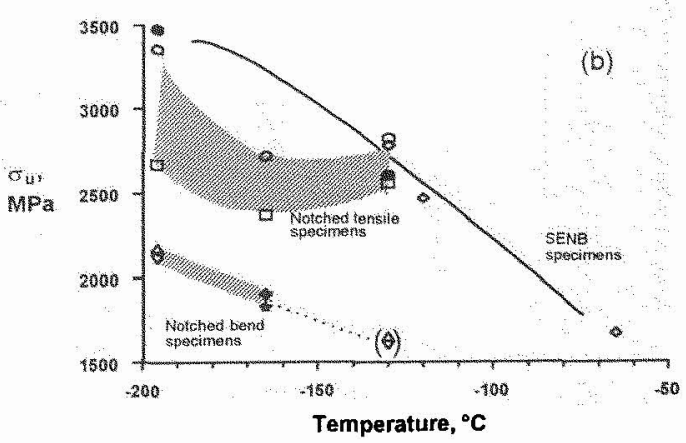

Fig.11 Effect of temperature on (a) Weibull shape parameter, $m$ and (b) Weibull scale parameter, $\sigma_{u}$, for different specimen geometries. 